\title{
Biologically active pigment and ShIA cytolysin of Serratia marcescens induce autophagy in a human ocular surface cell line
}

Kimberly M. Brothers, Nicholas A. Stella and Robert M. Q. Shanks

\begin{abstract}
Background: The cellular process of autophagy is essential for maintaining the health of ocular tissue. Dysregulation of autophagy is associated with several ocular diseases including keratoconus and macular degeneration. It is known that autophagy can be used to respond to microbial infections and that certain microbes can exploit the autophagic process to their benefit. In this study, a genetic approach was used to identify surfaceassociated and secreted products generated by the opportunistic pathogen Serratia marcescens involved in activation of autophagy.
\end{abstract}

Methods: A recombinant human corneal limbal epithelial cell line expressing a LC3-GFP fusion protein was challenged with normalized secretomes from wild-type and mutant S. marcescens derivatives. LC3-GFP fluorescence patterns were used to assess the ability of wild-type and mutant bacteria to influence autophagy. Purified prodigiosin was obtained from stationary phase bacteria and used to challenge ocular cells.

Results: Mutations in the global regulators eep $R$ and gumB genes highly reduced the ability of the bacteria to activate autophagy in corneal cells. This effect was further narrowed down to the secreted cytolysin ShIA and the biologically active pigment prodigiosin. Purified prodigiosin and ShIA from Escherichia coli further supported the role of these factors in activating autophagy in human corneal cells. Additional genetic data indicate a role for flagellin and type I pili, but not the nuclease, S-layer protein, or serratamolide biosurfactant in activation of autophagy.

Conclusions: This work identifies specific bacterial components that activate autophagy and give insight into potential host-pathogen interactions or compounds that can be used to therapeutically manipulate autophagy.

Keywords: Autophagy, Bacteria, Keratitis, Ocular surface, Epithelium, Cornea, Prodigiosin, Cytolysin, Flagella, Fimbriae

\footnotetext{
* Correspondence: shanksrm@upmc.edu

The Charles T. Campbell Ophthalmic Microbiology Laboratory, Department of Ophthalmology, University of Pittsburgh School of Medicine, EEl 1020, 203 Lothrop Street, Pittsburgh, Pennsylvania 15213, USA
}

(c) The Author(s). 2020 Open Access This article is licensed under a Creative Commons Attribution 4.0 International License, which permits use, sharing, adaptation, distribution and reproduction in any medium or format, as long as you give appropriate credit to the original author(s) and the source, provide a link to the Creative Commons licence, and indicate if changes were made. The images or other third party material in this article are included in the article's Creative Commons licence, unless indicated otherwise in a credit line to the material. If material is not included in the article's Creative Commons licence and your intended use is not permitted by statutory regulation or exceeds the permitted use, you will need to obtain permission directly from the copyright holder. To view a copy of this licence, visit http://creativecommons.org/licenses/by/4.0/ The Creative Commons Public Domain Dedication waiver (http://creativecommons.org/publicdomain/zero/1.0/) applies to the data made available in this article, unless otherwise stated in a credit line to the data. 


\section{Background}

Cells use autophagy to eliminate waste products such as damaged organelles and proteins in order to enhance survival during periods of starvation. Autophagy dysregulation has been linked to many diseases including those of the eye [1-7]. Therefore therapeutic control of autophagy has been suggested for treatment of cancer, metabolic diseases, neurodegenerative disorders, for management of cardiovascular aging, and even for treatment of corneal infections [8-10].

The role of autophagy in the cornea is less well understood, but it is clear that autophagy plays a role in HSV1 infection and keratoconus $[3,5,11]$. A recent study measured activation of autophagy in mouse corneas following infection with the fungus Aspergillus fumigatus and positively correlated autophagy with the severity of infectious pathology [12]. Similarly, data from a study using the bacterium Pseudomonas aeruginosa, suggest that it benefits from activating autophagy as a means of escaping extracellular killing in macrophages [13]. However, in general, activation of autophagy is thought to protect cells from microbial infection [14, 15]. It is known that a few bacterial proteins such as TlpE from $P$. aeruginosa, bacterial macrolide, rapamycin, TLRligands, and proinflammatory cytokines can activate autophagy [15-17], but knowledge of the scope of infectious components that activate autophagy is limited [15].
Our previous work has demonstrated that sterile culture filtrates (secretomes) of a number of ocular pathogens can activate autophagy in a human corneal limbal epithelial cell line [18], impede cell migration and wound closure [19], and cause cellular death in a bacterialstrain dependent manner $[20,21]$. These included secretomes gram positive bacteria such as Staphylococcus aureus and gram negative bacteria including Serratia marcescens [18]. The secreted or shed bacterial components detected by the corneal cells that activate autophagy were not determined. In this study we took advantage of our collection of $S$. marcescens defined mutants to identify bacterial factors that induce autophagy in corneal cells.

\section{Methods}

Analysis of autophagy induced by keratitis isolates

Bacterial stocks (Table 1) were stored at $-80^{\circ} \mathrm{C}$ and single colonies were obtained on lysogeny broth (LB) agar. Colonies were grown in $\mathrm{LB}$ at $30^{\circ} \mathrm{C}$ for $\sim 18 \mathrm{~h}$ with aeration on tissue culture rollers. Where noted, bacteria were grown with L-arabinose at $1 \mathrm{mM}$ for controlled expression of genes. Secretomes were prepared by normalizing overnight cultures to $\mathrm{OD}_{600}=2.0$, removal of bacteria by centrifugation at $14,000 \mathrm{rpm}$ and filtration through a $0.22 \mu \mathrm{m}$ filter (Millex PVDF). Normalized secretomes were added to HCLE cells at a ratio of $500 \mu \mathrm{l}$

Table 1 Bacteria and plasmids used in this study

\begin{tabular}{|c|c|c|}
\hline Strain or plasmid & Description & Reference or source \\
\hline Top10 & E. coli laboratory strain & ThermoFisher \\
\hline PIC3611 & Serratia marcescens wild-type strain & Presque Isle Cultures \\
\hline K904 & S. marcescens keratitis isolate & [22] \\
\hline CMS1722 & PIC3611 with pMQ262 (L-arabinose inducible pig) & [23] \\
\hline CMS2096 & PIC3611 $\triangle p i g A$ & [24] \\
\hline CMS2097 & PIC3611 $\triangle$ eepR & {$[25]$} \\
\hline CMS2229 & K904 pigD::tn & This study \\
\hline CMS2232 & K904 swrW::tn & {$[26]$} \\
\hline CMS2904 & K904 $\Delta e e p R$ & {$[25]$} \\
\hline CMS3559 & K904 nucA::tn & This study \\
\hline CMS3900 & K904 flic::pMQ192 & [27] \\
\hline CMS4001 & K904 $\triangle$ gumB & {$[28]$} \\
\hline CMS4225 & K904 fimC::pMQ167 & {$[27]$} \\
\hline CMS4236 & K904 $\triangle s h / B$ & {$[20]$} \\
\hline CMS4334 & K904 sh/A::tn & {$[20]$} \\
\hline CMS4413 & K904 $\Delta$ slaA & [29] \\
\hline CMS4773 & K904 $\triangle$ shlB pigE::.tn & This study \\
\hline \multicolumn{3}{|l|}{ Plasmids } \\
\hline pMQ125 & expression vector with L-arabinose inducible promoter & {$[30]$} \\
\hline pMQ492 & pMQ125 with shIBA operon from S. marcescens & [20] \\
\hline
\end{tabular}


per $1 \mathrm{ml}$ of tissue culture medium (KSFM) and incubated at $37^{\circ} \mathrm{C}+5 \% \mathrm{CO}_{2}$ for $3 \mathrm{~h}$. In some cases secretomes were further diluted 2-fold $\left(\mathrm{OD}_{600}=1.0\right)$ due to excessive cytotoxicity as noted in the text. The autophagy inhibitor 3-methyladenine (3MA) was added to culture media at $5 \mathrm{mM}$, one hour prior to challenge with secretomes as previously described [18, 31].

To analyze autophagy, LC3-GFP HCLE cells [18] were imaged with 60X magnification on an Olympus IX-81 inverted confocal microscope with Fluoview imaging software. The LC3-GFP cells were generated by lentiviral transduction of the human corneal limbal epithelial cell line from Ilene Gipson [32]. Image J (NIH) was used to quantify images without any image adjustment. Autophagy levels were quantified following recommendations of Klionsky et al. [33] in which the standard deviation of fluorescent pixel intensity of a cell is divided by its mean pixel intensity of the cell. Two to three fields per treatment condition were imaged. The experiment was repeated on at least two different days and at least 50 cells were analyzed per group. The data was averaged from all fields taken per experiment and graphed using GraphPad prism. One way ANOVA with Tukey's post hoc analysis was used to determine statistical significance at $P<0.05$ unless otherwise stated.

\section{Generation of new mutants strains}

Additional mutants (Table 1) were generated by transposon mutagenesis using the pSC189 mariner transposon delivery system as previously described [34, 35]. Transposons were mapped using the method of Chiang, et al. [34] To identify nuclease defective mutants, libraries of mutants were transferred from 96-well plates to DNase detection agar (BD Difco) and plates were screened for loss of nuclease zones after $16-20 \mathrm{~h}$ of incubation at $30^{\circ} \mathrm{C}$ around individual colonies. The transposon was mapped to $89 \mathrm{bp}$ upstream of the $n u c A$ open reading frame and results in an almost complete loss of secreted nuclease activity (data not shown). Mutations in the prodigiosin biosynthetic operon were obtained by visually screening mutant libraries of strain K904 and K904 $\Delta$ shlB for loss of pigment. Transposon insertions were mapped to base pair 2451 in the K904 strain background and to base pair 1075 of pigE in the $\triangle$ shlB strain background.

\section{Purification of prodigiosin}

Wild-type strain PIC3611 and an isogenic $\Delta p i g A$ strain were grown overnight in LB broth with aeration. The $\triangle p i g A$ mutant does not make prodigiosin and served as a negative control. Bacteria were adjusted to $\mathrm{OD}_{600}=4$, aliquots $(5 \mathrm{ml})$ were pelleted by centrifugation $(7000$ RPM for $10 \mathrm{~min}$ ), and supernatants were removed. To extract prodigiosin, bacterial cells were suspended in $100 \mu \mathrm{l}$ of acidified ethanol $(2 \mathrm{ml}$ of $2 \mathrm{M} \mathrm{HCl}$ in $98 \mathrm{ml}$ of
95\% ethanol) and incubated for one hour with periodic vortexing. Samples were further purified with hydroxyapatite resin. Columns were packed with hydroxyapatite resin (BioRad \#16260), equilibrated with acidified ethanol, and samples were run through the columns with acidified ethanol. The mock purification sample from the $\triangle p i g A$ culture was collected at the same time as the prodigiosin fraction from the wild type was collected. Samples were air-dried and prodigiosin concentration was determined using a standard curve of absorbance at $534 \mathrm{~nm}$ using commercial prodigiosin as a standard (Sigma). The same volume of prodigiosin was added from the wild type and $\triangle p i g A$-derived samples.

\section{Results}

S. marcescens secretome induction of autophagy is inhibited by 3-methyladenine

Our previous study showed that a subset of ocular bacterial pathogens induced autophagy in a corneal cell line, and that among the strongest induction was observed with $S$. marcescens [18]. In this study, we set out to determine which components of $S$. marcescens using wild-type and genetically manipulated strains induced formation of LC3GFP puncta. We used two S. marcescens strains: strain PIC3611 from Presque Isle Culture collection, a laboratory strain that is likely from an environmental source (biotype TCT), and K904, a contact lens associated keratitis isolate (biotype A6a). Two strains were used to determine whether phenotypes were associated with one particular strain or a more general phenomenon.

Figure 1 demonstrates activation of autophagy following exposure of HCLE LC3-GFP cells to normalized filtered supernatants (secretomes) from strain PIC3611 Fig. 1a, b). The formation of LC3-GFP puncta indicate cells with activated autophagy and can be used in quantification of autophagy [33]. Autophagy stimulation by PIC3611 secretomes could be prevented using autophagy inhibitor 3-methyladenine (3MA), supporting that the observed LC3-GFP phenotype is autophagy dependent (Fig. 1). The same trend was previously shown for strain K904 and with the use of autophagy inhibitor baflomycin [18]. As an additional control to show that LC3-GFP puncta are not an artifact of fluorescent bacterial components, an HCLE-GFP cell line with no LC3 fusion was used [18]. Following PIC3611 supernatant treatment, no fluorescent focus formation was observed from the GFP control cell line (Fig. 1c).

\section{S. marcescens secondary metabolite regulators are necessary for activation of autophagy}

The component(s) of the secretome responsible for autophagy induction is unknown. Our previous study 

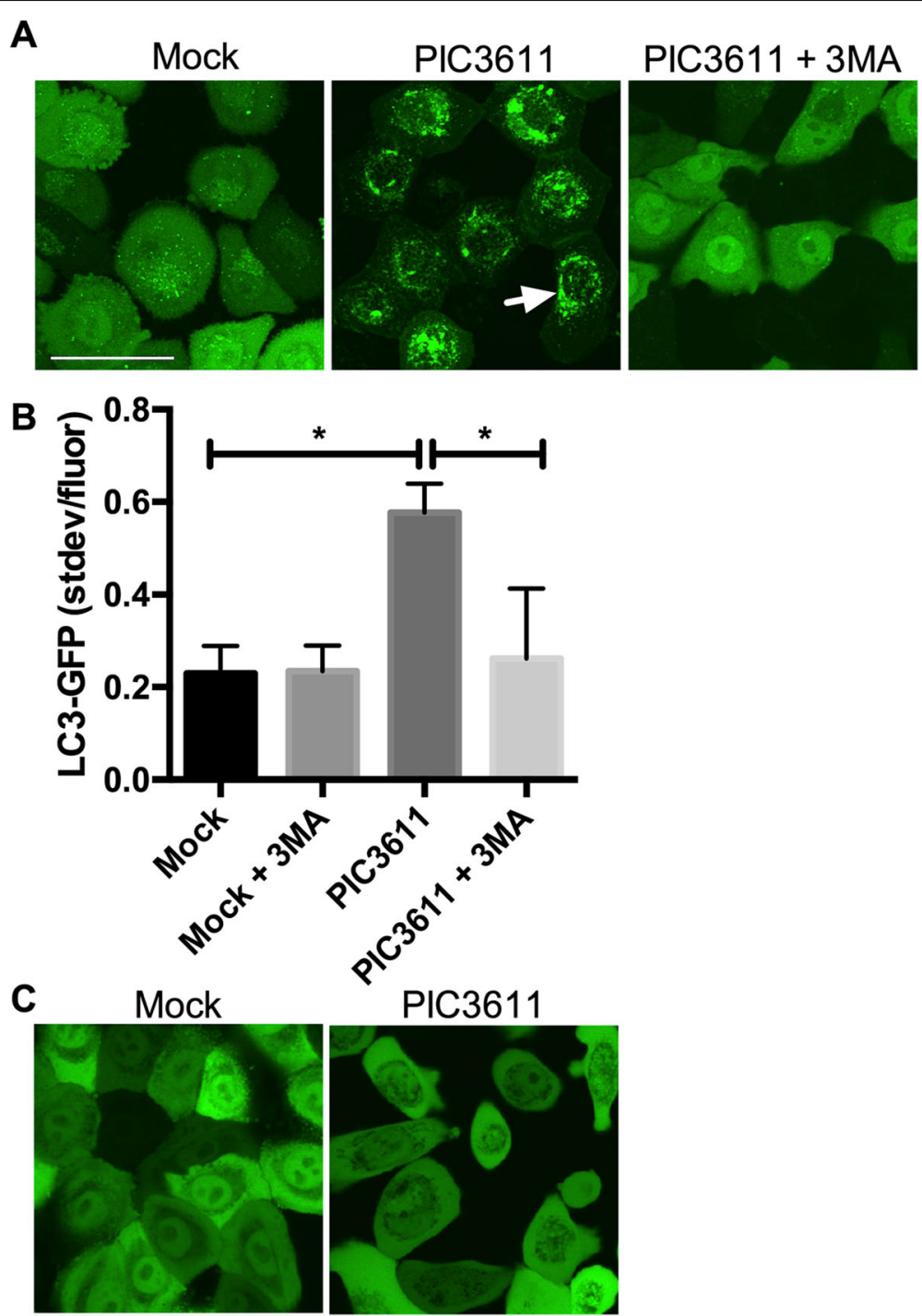

Fig. 1 Induction of autophagy in a corneal cell line by S. marcescens. a. Activation of autophagy by secretome of wild-type strain PIC3611 that can be reversed by addition of autophagy inhibitor 3-methyladenine (3MA). Representative confocal images of HCLE LC3-GFP cells exposed to LB medium (mock), secretome from PIC3611, or secretome with autophagy inhibitor. White arrow indicates LC3-GFP puncta and scale bar $=50 \mu \mathrm{m}$. b. Autophagy levels were measured using LC3-GFP patterns. Averages and standard deviations are shown, $n>50$ cells per group. Asterisks denote significant differences using ANOVA with Tukey's post-test $(p<0.05)$. c. Representative confocal images of HCLE-GFP cells showing no puncta after being exposed to PIC3611 secretomes

demonstrated that secretomes could be heated at $95^{\circ} \mathrm{C}$ and still induce autophagy [18]. Well-defined S. marcescens strains with deletion mutations in the eepR and gumB genes were tested for loss of autophagy induction because these genes have a conserved and broad impact on $S$. marcescens biology [20, 24, 25, 28, 36]. The EepR and GumB genes regulate expression of multiple secreted factors including heat-stable secondary metabolites such as the biologically active pigment prodigiosin and the hemolytic and antimicrobial biosurfactant serratamolide. Both the eepR and $g u m B$ mutants were defective in activation of autophagy (Fig. 2a).
Additionally, secretomes from strains with mutations in a variety of surface or secreted proteins regulated by EepR and/or GumB were individually tested in the K904 strain background (Figs. $2 \mathrm{~b}$ and 3 ). These include the type 1 pilus gene, fim $C$, the flagellin gene, $f l i C$, the secreted nuclease gene, $n u c A$, the prodigiosin biosynthetic gene, pigD, the cytolysin, $s h l A$, the outer membrane cytolysin transporter gene $s h l B$, the S-layer protein gene, sla $A$, and the serratamolide biosynthetic gene, $s w r W$.

Mutant analysis suggested that the eepR and $g u m B$ mutants share a defect in autophagy induction with a subset of the mutants (Figs. 2b and 3), most notably pigD, which 

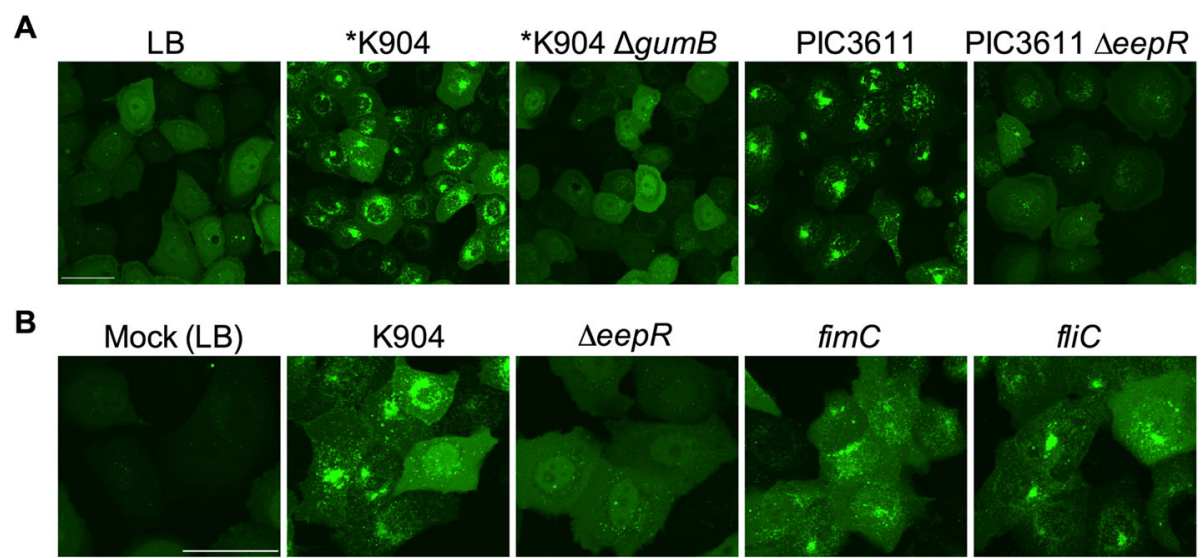

K904

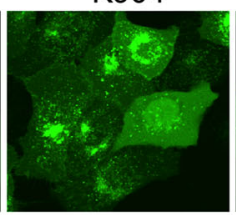

$\Delta e e p R$

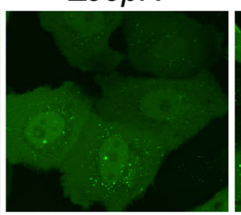

fimC

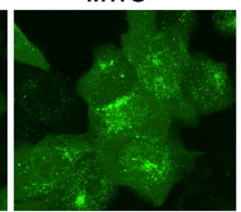

fil

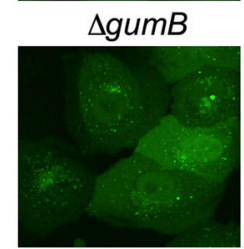

nucA

pigD
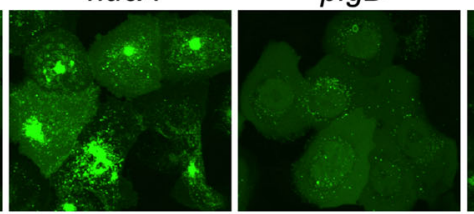

shlA

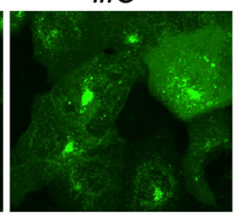

$\Delta s h \mid B$ pigD

$\Delta s / a A$

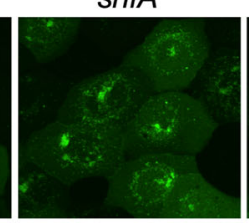

$\Delta s h l B$
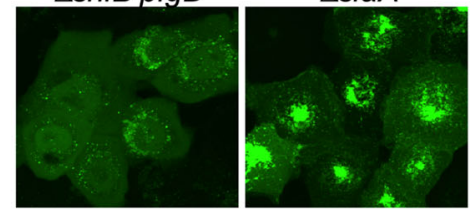

swrW

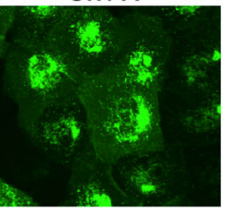

Fig. 2 a. Activation of autophagy by S. marcescens secretomes. Images of LC3-GFP puncta in HCLE cells treated with secretomes. $O D_{600}={ }^{*} 0.5$ secretomes used in the shown experiment. Scale bar $=50 \mu \mathrm{m}$. b. Activation of autophagy by secretomes from various isogenic mutants in the K904 strain background. Scale bar $=50 \mu \mathrm{m}$

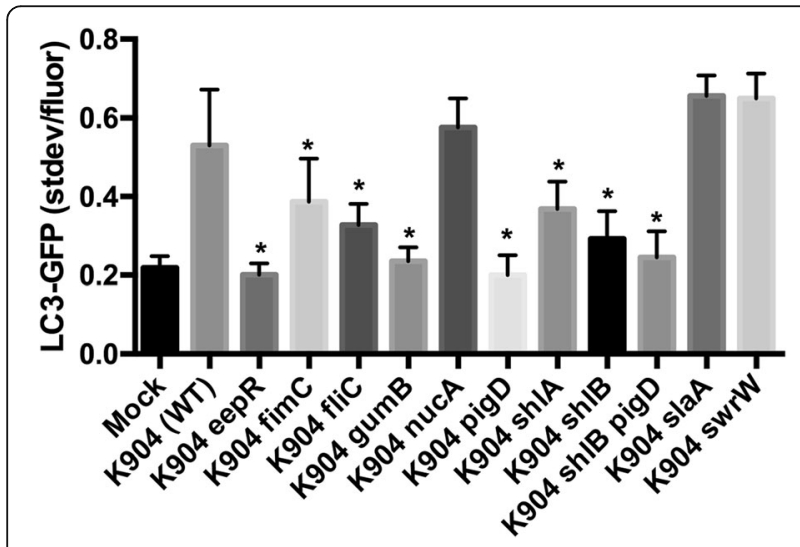

Fig. 3 S. marcescens mutants unable to secrete prodigiosin pigment or ShIA cytolysin are defective in inducing autophagy. Activation of autophagy by wild-type secretome (K904) and isogenic mutants or mock (LB medium). Asterisks denote significant differences from wild-type strain K904 using ANOVA with Tukey's post-test $(p<0.05)$. Averages and standard deviations are shown, $n>50$ cells per group codes for a gene involved in prodigiosin pigment biosynthesis [37]. Both eepR and gumB are severely defective in prodigiosin production due to reduced transcription of the prodigiosin biosynthetic genes, implicating prodigiosin as a stimulatory factor $[25,28]$. Secretomes from mutants unable to make type 1 pili, flagella, and cytolysin / cytolysin transporter ( $s h l A$ and $s h l B$, respectively) were also defective, but to a lesser extent then the pigment mutants.

\section{Prodigiosin is necessary and sufficient to induce autophagy in a corneal cell line}

Given that the prodigiosin defective mutants, eepR, $\operatorname{gumB}$, and pigD were defective in inducing autophagy whether they were from the PIC3611 (Fig. 2a) or K904 background (Figs. 2a, b and 3), we analyzed whether prodigiosin played a role in inducing autophagy in the HCLE LC3-GFP cell line in greater depth. First, because the eepR mutation confers pleiotropic effects, we compared the wild-type strain PIC3611 with an isogenic mutant unable to make PigA, which is required for prodigiosin biosynthesis. Similar to the eepR mutant, when only pigment biosynthesis was ablated through deletion of the pigA gene, strain PIC3611 was unable to induce autophagy (Fig. 4a). 


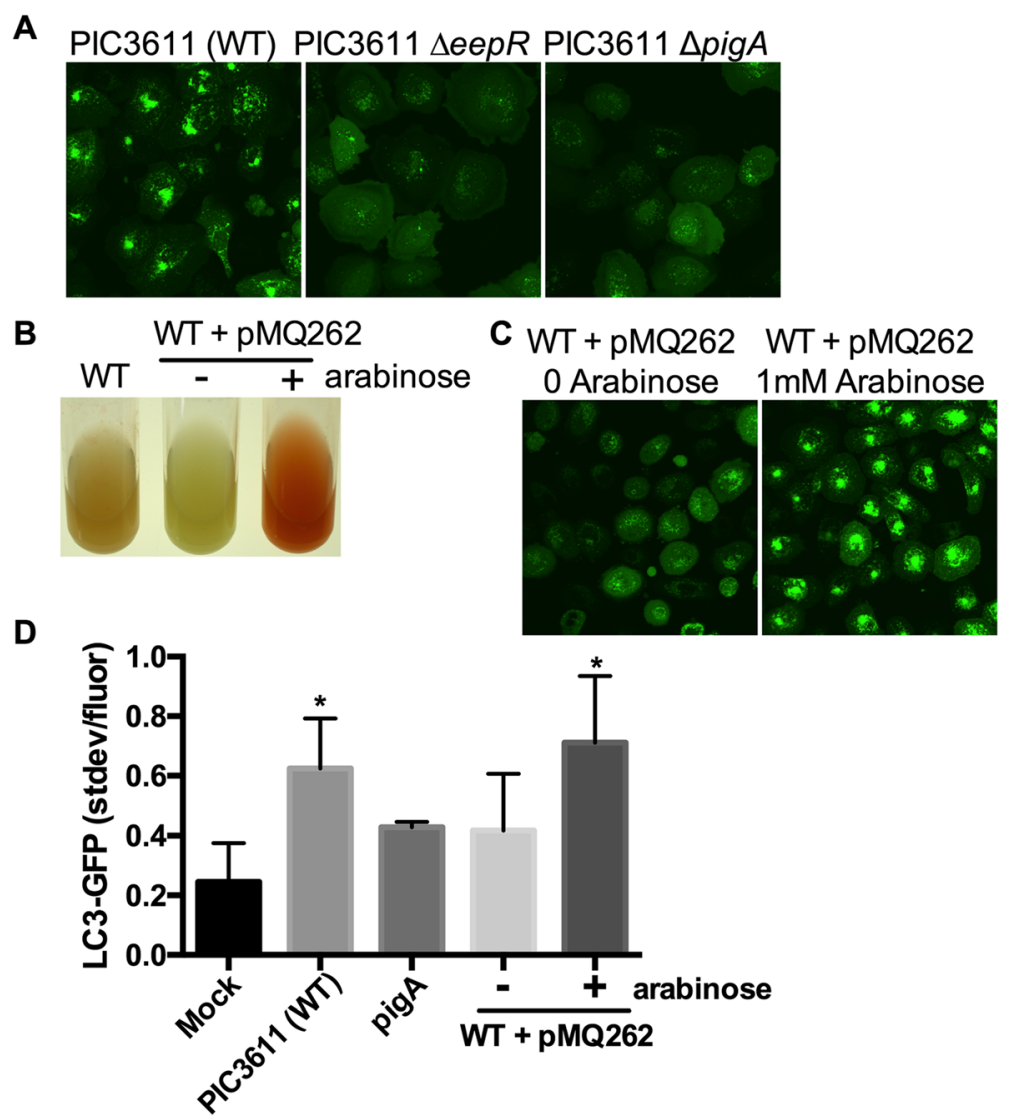

Fig. 4 Prodigiosin biosynthetic genes are necessary for maximal autophagy induction by S. marcescens strain PIC3611. a. The pigA pigment biosynthetic gene is required for strain PIC3611 to induce autophagy and is defective to a similar level as the eepR mutant. b. Image of cultures of S. marcescens strain PIC3611 or PIC3611 with pMQ262 grown for $18 \mathrm{~h}$ without or with L-arabinose $(1 \mathrm{mM})$, which activates prodigiosin biosynthetic gene transcription. Prodigiosin pigment is visible as orange to red coloration. $\mathbf{c}$. Confocal images of LC3-GFP puncta activated by WT (PIC3611) + pMQ262 secretomes that had been grown with arabinose. $\mathbf{d}$. Analysis of autophagy demonstrates a requirement for prodigiosin biosynthetic genes. Asterisks denote significant differences from the PIC3611 $\triangle p i g A$ mutant using ANOVA with Tukey's post-test $(p<0.05)$. Averages and standard deviations are shown, $n>50$ cells per group

We have previously described the use of plasmid pMQ262, which replaces the normal pigment biosynthetic promoter with an arabinose inducible promoter $[26,38]$, such that prodigiosin pigment biosynthesis is dependent upon arabinose in the growth medium (Fig. 4b). When secretomes from strain PIC3611 with pMQ262 were used to challenge HCLE LC3-GFP cells, the ability to activate autophagy correlated with arabinose induction of pigment production (Fig. 4c). Arabinose, itself, did not induce autophagy (data not shown). These data suggest that prodigiosin is necessary for $S$. marcescens secretomes to fully activate autophagy in corneal cells.

To test whether prodigiosin was sufficient for activation of autophagy in HCLE LC3-GFP cell line, we purified prodigiosin from strain PIC3611 and mock purified it from the isogenic $\triangle p i g A$ mutant, and tested these for activation of LC3-GFP puncta formation (Fig. 5a-b). Prodigiosin from PIC3611 $(0.9 \mu \mathrm{M})$ was able to activate autophagy. The negative control mock purified prodigiosin from the $\triangle p i g A$ mutant was unable to activate autophagy when added at the same volume. Similarly, commercially available prodigiosin could activate autophagy in a dose dependent manner (Fig. 5a, c).

\section{Analysis of the ShlA cytolysin in inducing autophagy from corneal cells}

Data from genetic analysis above suggested that the pore forming cytolysin, ShlA, contributes to autophagy induction (Figs. $2 \mathrm{~b}$ and 3 ). The ShlB protein is necessary for secretion of ShlA, such that shlB mutants do not secrete ShlA [39]. Consistently, the tested $s h l B$ mutant behaved similarly to the shlA mutant (Fig. 2b, and Fig. 3). We generated a double mutant that is unable to make prodigiosin or secrete ShlA ( $\triangle \operatorname{shlB}$ pigD), and this was indistinguishable from the pigD mutant, but had a trend to lower levels of autophagy induction compared to the $\Delta$ shlB levels. 

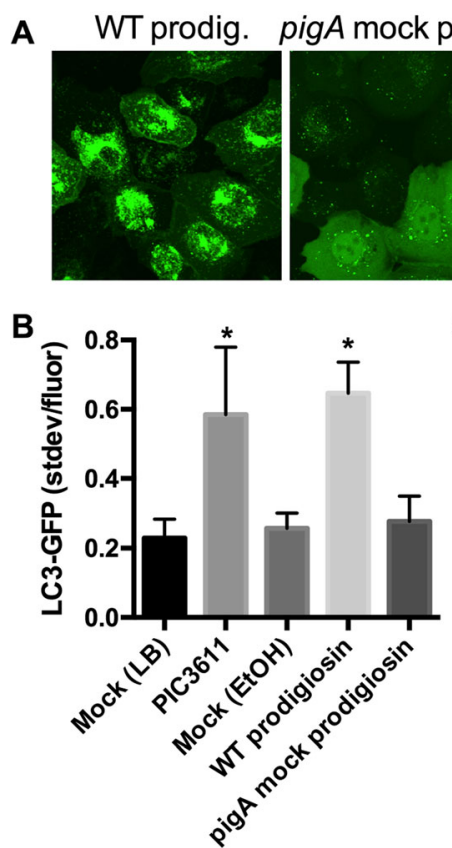
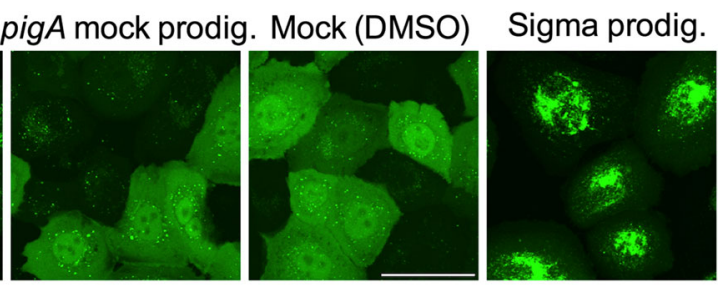

C

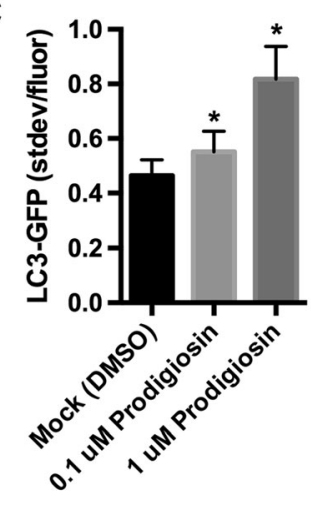

Fig. 5 Prodigiosin is sufficient to induce autophagy in the corneal HCLE LC3-GFP cell line. a. Confocal images of HCLE LC3-GFP cells challenged with prodigiosin from wild-type PIC3611, the $\triangle$ pigA mutant, or from a commercial source (1 mM). b. Autophagy activation by WT PIC3611 secretome and prodigiosin purified from the WT but not isogenic $\triangle$ pigA mutant. c. Commercially available prodigiosin induces autophagy. Asterisks denote significant differences from Mock groups using ANOVA with Tukey's post-test $(p<0.05)$. Averages and standard deviations are shown, $n>50$ cells per group

Our previous study detected moderate activation of autophagy by a clinical keratitis isolate of $E$. coli in HCLE-GFP cells [18] and that E. coli with a shlBA plasmid (pMQ492) is able to secrete functional ShlA cytolysin [20]. Here, we observed that ectopic expression of the $S$. marcescens shlBA operon increased the ability of $E$. coli secretomes to induce autophagy in HCLE LC3GFP cells (Fig. 6). Together, these results indicate a role for the ShlA cytolysin in activation of autophagy.

\section{Discussion}

Several studies have explored the role of ocular autophagy with HSV-1, Toxoplasma gondii, and fungal spp. [2, 3 , 5] However, the role of ocular autophagy in response to bacterial pathogens remains poorly understood.

This study demonstrated that two strains of $S$. marcescens from different biotypes were capable of activating autophagy in a corneal cell line and identified bacterial factors capable of activating autophagy. Mutations in two different genes that confer major pleiotropic effects on $S$. marcescens behavior, eepR and $g u m B$, prevented bacterial activation of autophagy. The eepR gene is a transcription factor that is required for wild-type levels bacterial proliferation in a rabbit keratitis model as well as positive regulation of secondary metabolites such as prodigiosin and serratamolide [24, 25]. The gumB gene codes for a stress response signal transmitting protein that positively regulates prodigiosin and serratamolide, and is necessary for production of the ShlA, ShlB, and flagellin [20, 28]. We therefore tested individual genes controlled by EepR and GumB and identified several bacterial factors that activate autophagy.

Our genetic and biochemical results indicate that prodigiosin can activate autophagy in the tested human corneal cell line. Prodigiosin, 2-methyl-3-pentyl-6-methoxyprodiginine, is thought to contribute to bacterial competition, and has antitumor capabilities [37, 40, 41]. Furthermore, prodigiosin was recently shown to activate autophagic cell death in a variety of cancer cell lines and to reduce tumor proliferation in mouse tracheas [42-49]. Many clinical isolates of S. marcescens do not synthesize prodigiosin [50], and perhaps this benefits them by reducing activation of the host's innate immune response.

Beyond prodigiosin, data from this study implicated the ShlA cytolysin in activation of autophagy in corneal cells. Similarly, in an elegant study by the Véscovi group, the pore forming cytolysin ShlA was demonstrated to induce autophagy in Chinese hamster ovary (CHO) cells [51].

In contrast to our work that suggested a role for flagellin as an autophagy inducer, Di Venanzio showed that $S$. marcescens with mutations in fliA and $f l h D$, which should be defective in flagella production, were able to activate autophagy in $\mathrm{CHO}$ cells [51]. These differences may be due to the specific bacterial strain background 


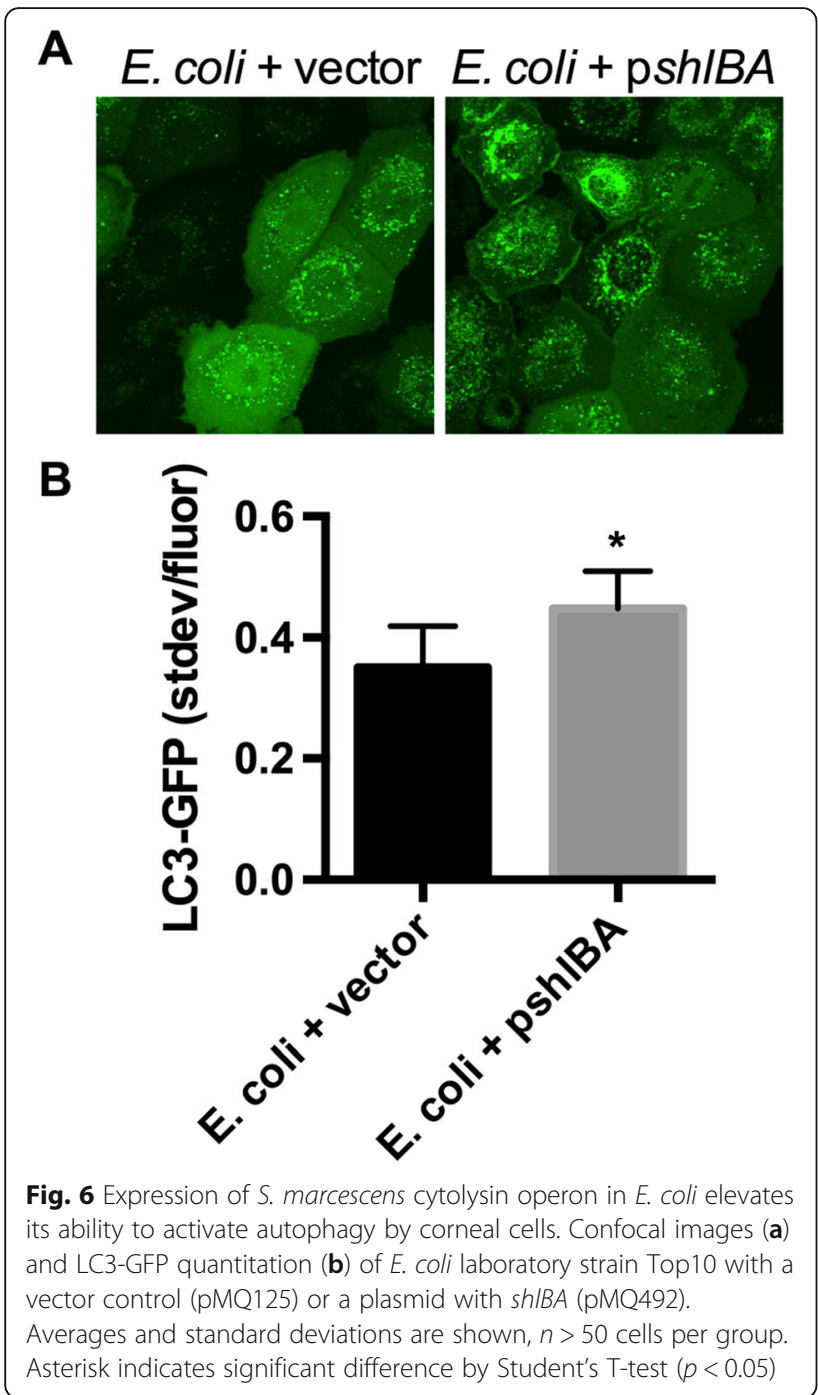

or use of $\mathrm{CHO}$ cells versus corneal cells. However, consistent with our finding, data from a recent papers using Salmonella, implicated flagellin as an activator of autophagy in zebrafish and murine RAW cells $[52,53]$. To our knowledge there is no previous information on fimbriae / type I pili in activation of autophagy. It is also formally possible that some of the increase in LC3-GFP puncta results from a reduction in autophagic flux leading to the increase in overall autophagosomes. The impact of these bacterial factors on autophagic flux will be tested in subsequent studies.

\section{Conclusions}

We have identified S. marcescens activators of autophagy. Whereas prodigiosin and ShlA from S. marcescens have been previously implicated in activating autophagy, this report is the first to demonstrate this with ocular derived cells. The ability of flagellin and fimbria to induce autophagy will need to be further validated using biochemical means, but this report identifies these bacterial factors as potential microbial mediators of autophagy in corneal cells. Since $S$. marcescens is most commonly associated with the eye as a contact lens associated pathogen, it is possible that corneal cells prime themselves for microbial infection through sensing prodigiosin, flagellin, fimbriae, and ShlA toxins.

\section{Abbreviations}

3MA: 3-methyladenine, autophagy inhibitor; ANOVA: Analysis of variance, statistical analysis; CHO: Chinese hamster ovary, cell line; GFP: Green fluorescent protein; HCLE: Human corneal limbal epithelial, cell line; RPM: Rotations per minute

\section{Acknowledgements}

The authors would like to thank Grace Altimus, Marissa Aston, Jake Callaghan, Mitchell Meyer and Hazel Shanks for technical help or critical reading of the manuscript.

Authors' contributions

Writing and editing of manuscript: NAS, KB, RMQS; Study design: KB and RMQS; Data collection NAS, KB; Analysis and interpretation of data KB and RMQS. All authors read and approved the final manuscript.

\section{Funding}

This work was supported by unrestricted funds from Research to Prevent Blindness, the Eye and Ear Foundation of Pittsburgh, and the National Institute of Health grants EY08098 and EY027331. The funding agencies played no role in the design of the study, the collection, analysis, and interpretation of data and in the writing of the manuscript.

\section{Availability of data and materials}

The datasets used during this current study are available from the corresponding author on reasonable request.

Ethics approval and consent to participate

The use of recombinant DNA materials was approved by the University of Pittsburgh Institutional Biosafety Committee.

\section{Consent for publication}

Not applicable.

\section{Competing interests}

Robert MQ Shanks is an Associate Editor of BMC Ophthalmology.

Received: 10 January 2020 Accepted: 12 March 2020

Published online: 26 March 2020

\section{References}

1. Boya P, Esteban-Martinez L, Serrano-Puebla A, Gomez-Sintes R, Villarejo-Zori B. Autophagy in the eye: development, degeneration, and aging. Prog Retin Eye Res. 2016;55:206-45.

2. Chai $\mathrm{P}, \mathrm{Ni} \mathrm{H}$, Zhang $\mathrm{H}$, Fan $\mathrm{X}$. The evolving functions of autophagy in ocular health: a double-edged sword. Int J Biol Sci. 2016;12(11):1332-40.

3. Frost LS, Mitchell CH, Boesze-Battaglia K. Autophagy in the eye: implications for ocular cell health. Exp Eye Res. 2014;124:56-66.

4. Kaarniranta K, Sinha D, Blasiak J, Kauppinen A, Vereb Z, Salminen A, Boulton ME, Petrovski G. Autophagy and heterophagy dysregulation leads to retinal pigment epithelium dysfunction and development of age-related macular degeneration. Autophagy. 2013;9(7):973-84.

5. Martin LM, Jeyabalan N, Tripathi R, Panigrahi T, Johnson PJ, Ghosh A, Mohan RR. Autophagy in corneal health and disease: a concise review. Ocul Surf. 2019;17(2):186-97

6. Moreno ML, Merida S, Bosch-Morell F, Miranda M, Villar VM. Autophagy dysfunction and oxidative stress, Two Related Mechanisms Implicated in Retinitis Pigmentosa. Front Physiol. 2018;9:1008.

7. Russo R, Nucci C, Corasaniti MT, Bagetta G, Morrone LA. Autophagy dysregulation and the fate of retinal ganglion cells in glaucomatous optic neuropathy. Prog Brain Res. 2015;220:87-105. 
8. Moon EK, Kim SH, Hong Y, Chung DI, Goo YK, Kong HH. Autophagy inhibitors as a potential antiamoebic treatment for Acanthamoeba keratitis. Antimicrob Agents Chemother. 2015;59(7):4020-5.

9. Ren J, Sowers JR, Zhang Y. Metabolic stress, autophagy, and cardiovascular aging: from pathophysiology to therapeutics. Trends Endocrinol Metab. 2018:29(10):699-711.

10. Rubinsztein DC, Codogno P, Levine B. Autophagy modulation as a potential therapeutic target for diverse diseases. Nat Rev Drug Discov. 2012;11(9):70930

11. Jiang Y, Yin X, Stuart PM, Leib DA. Dendritic Cell Autophagy Contributes to Herpes Simplex Virus-Driven Stromal Keratitis and Immunopathology. mBio. 2015;6(6):e01426-15.

12. Li CY, Li C, Li H, Zhao GQ, Lin J, Wang Q, Peng XD, Xu Q, Zhu GQ, Jiang JQ. Disparate expression of autophagy in corneas of C57BL/6 mice and BALB/C mice after Aspergillus fumigatus infection. Int J Ophthalmol. 2019;12(5):70510.

13. Deng $Q$, Wang Y, Zhang Y, Li M, Li D, Huang X, Wu Y, Pu J, Wu M. Pseudomonas aeruginosa triggers macrophage autophagy to escape intracellular killing by activation of the NLRP3 Inflammasome. Infect Immun. 2016;84(1):56-66

14. Choi AM, Ryter SW, Levine B. Autophagy in human health and disease. N Engl J Med. 2013;368(7):651-62.

15. Jiao Y, Sun J. Bacterial manipulation of Autophagic responses in infection and inflammation. Front Immunol. 2019;10:2821.

16. Delgado M, Singh S, De Haro S, Master S, Ponpuak M, Dinkins C, Ornatowski W, Vergne I, Deretic V. Autophagy and pattern recognition receptors in innate immunity. Immunol Rev. 2009;227(1):189-202.

17. Yang YP, Hu LF, Zheng HF, Mao CJ, Hu WD, Xiong KP, Wang F, Liu CF. Application and interpretation of current autophagy inhibitors and activators. Acta Pharmacol Sin. 2013;34(5):625-35.

18. Brothers KM, Kowalski RP, Tian S, Kinchington PR, Shanks RMQ. Bacteria induce autophagy in a human ocular surface cell line. Exp Eye Res. 2018 168:12-8.

19. Brothers KM, Stella NA, Hunt KM, Romanowski EG, Liu X, Klarlund JK, Shanks RM. Putting on the brakes: bacterial impediment of wound healing. Sci Rep. 2015;5:14003.

20. Brothers KM, Callaghan JD, Stella NA, Bachinsky JM, AlHigaylan M, Lehner KL, Franks JM, Lathrop KL, Collins E, Schmitt DM, et al. Blowing epithelial cell bubbles with GumB: ShlA-family pore-forming toxins induce blebbing and rapid cellular death in corneal epithelial cells. PLoS Pathog. 2019;15(6): e1007825.

21. Shanks RM, Stella NA, Hunt KM, Brothers KM, Zhang L, Thibodeau PH. Identification of SlpB, a cytotoxic protease from Serratia marcescens. Infect Immun. 2015;83(7):2907-16.

22. Kalivoda EJ, Stella NA, Aston MA, Fender JE, Thompson PP, Kowalski RP, Shanks RM. Cyclic AMP negatively regulates prodigiosin production by Serratia marcescens. Res Microbiol. 2010;161(2):158-67.

23. Shanks RM, Dashiff A, Alster JS, Kadouri DE. Isolation and identification of a bacteriocin with antibacterial and antibiofilm activity from Citrobacter freundii. Arch Microbiol. 2012;194(7):575-87.

24. Brothers KM, Stella NA, Romanowski EG, Kowalski RP, Shanks RM. EepR mediates secreted protein production, desiccation survival, and proliferation in a corneal infection model. Infect Immun. 2015:83(11):4373-82.

25. Stella NA, Lahr RM, Brothers KM, Kalivoda EJ, Hunt KM, Kwak DH, Liu X, Shanks RM. Serratia marcescens cyclic AMP-receptor protein controls transcription of EepR, a novel regulator of antimicrobial secondary metabolites. J Bacteriol. 2015;197(15):2468-78.

26. Kadouri DE, Shanks RM. Identification of a methicillin-resistant Staphylococcus aureus inhibitory compound isolated from Serratia marcescens. Res Microbiol. 2013;164(8):821-6.

27. Shanks RM, Stella NA, Brothers KM, Polaski DM. Exploitation of a "hockeypuck" phenotype to identify pilus and biofilm regulators in Serratia marcescens through genetic analysis. Can J Microbiol. 2016;62(1):83-93.

28. Stella NA, Brothers KM, Callaghan JD, Passerini AM, Sigindere C, Hill PJ, Liu X, Wozniak DJ, Shanks RMQ. An IgaA/UmoB-family protein from Serratia marcescens regulates motility, capsular polysaccharide, and secondary metabolite production. Appl Environ Microbiol. 2018;84(6):e02575-17.

29. Garcia CJ, Pericleous A, Elsayed M, Tran M, Gupta S, Callaghan JD, Stella NA, Franks JM, Thibodeau PH, Shanks RMQ, et al. Serralysin family metalloproteases protects Serratia marcescens from predation by the predatory bacteria Micavibrio aeruginosavorus. Sci Rep. 2018;8(1):14025.
30. Shanks RM, Caiazza NC, Hinsa SM, Toutain CM, O'Toole GA. Saccharomyces cerevisiae-based molecular tool kit for manipulation of genes from gramnegative bacteria. Appl Environ Microbiol. 2006;72(7):5027-36.

31. Wu YT, Tan HL, Shui G, Bauvy C, Huang Q, Wenk MR, Ong CN, Codogno P, Shen HM. Dual role of 3-methyladenine in modulation of autophagy via different temporal patterns of inhibition on class I and III phosphoinositide 3-kinase. J Biol Chem. 2010;285(14):10850-61.

32. Gipson IK, Spurr-Michaud S, Argüeso P, Tisdale A, Ng TF, Russo CL. Mucin gene expression in immortalized human conreal-limbal and conjunc tival epithelial cell lines. Invest Ophthalmol Vis Sci. 2003;44(6):2496-506.

33. Klionsky DJ, Abdelmohsen K, Abe A, Abedin MJ, Abeliovich H, Acevedo Arozena A, Adachi H, Adams CM, Adams PD, Adeli K, et al. Guidelines for the use and interpretation of assays for monitoring autophagy (3rd edition). Autophagy. 2016;12(1):1-222.

34. Chiang SL, Rubin EJ. Construction of a mariner-based transposon for epitope-tagging and genomic targeting. Gene. 2002;296(1-2):179-85.

35. Shanks RM, Stella NA, Kalivoda EJ, Doe MR, O'Dee DM, Lathrop KL, Guo FL, Nau GJ. A Serratia marcescens OxyR homolog mediates surface attachment and biofilm formation. J Bacteriol. 2007:189(20):7262-72.

36. Stella NA, Callaghan JD, Zhang L, Brothers KM, Kowalski RP, Huang JJ, Thibodeau PH, Shanks RMQ. SlpE is a calcium-dependent cytotoxic metalloprotease associated with clinical isolates of Serratia marcescens. Res Microbiol. 2017;168(6):567-74.

37. Williamson NR, Fineran PC, Leeper FJ, Salmond GP. The biosynthesis and regulation of bacterial prodiginines. Nat Rev Microbiol. 2006;4(12):887-99.

38. Haddix PL, Shanks RMQ. Prodigiosin pigment of Serratia marcescens is associated with increased biomass production. Arch Microbiol. 2018;200(7): 989-99.

39. Hertle R. Serratia type pore forming toxins. Curr Protein Pept Sci. 2000;1 (1): 75-89.

40. Hage-Hulsmann J, Grunberger A, Thies S, Santiago-Schubel B, Klein AS, Pietruszka J, Binder D, Hilgers F, Domrose A, Drepper T, et al. Natural biocide cocktails: combinatorial antibiotic effects of prodigiosin and biosurfactants. PLoS One. 2018;13(7):e0200940.

41. Perez-Tomas R, Montaner B, Llagostera E, Soto-Cerrato V. The prodigiosins, proapoptotic drugs with anticancer properties. Biochem Pharmacol. 2003;66: 1447-52.

42. Cheng MF, Lin CS, Chen YH, Sung PJ, Lin SR, Tong YW, Weng CF. Inhibitory Growth of Oral Squamous Cell Carcinoma Cancer via Bacterial Prodigiosin. Mar Drugs. 2017;15(7).

43. Klein AS, Domrose A, Bongen P, Brass HUC, Classen T, Loeschcke A, Drepper T, Laraia L, Sievers S, Jaeger KE, et al. New Prodigiosin derivatives obtained by Mutasynthesis in Pseudomonas putida. ACS Synth Biol. 2017;6(9):1757-65.

44. Lin SR, Fu YS, Tsai MJ, Cheng H, Weng CF. Natural Compounds from Herbs that can Potentially Execute as Autophagy Inducers for Cancer Therapy. Int J Mol Sci. 2017;18(7).

45. Cheng SY, Chen NF, Kuo HM, Yang SN, Sung CS, Sung PJ, Wen ZH, Chen WF. Prodigiosin stimulates endoplasmic reticulum stress and induces autophagic cell death in glioblastoma cells. Apoptosis. 2018;23(5-6):314-28.

46. Chiu WJ, Lin SR, Chen YH, Tsai MJ, Leong MK, Weng CF. ProdigiosinEmerged PI3K/Beclin-1-Independent Pathway Elicits Autophagic Cell Death in Doxorubicin-Sensitive and -Resistant Lung Cancer. J Clin Med. 2018;7(10).

47. Davient B, Ng JPZ, Xiao Q, Li L, Yang L. Comparative Transcriptomics unravels Prodigiosin's potential Cancer-specific activity between human small airway epithelial cells and lung adenocarcinoma cells. Front Oncol. 2018;8:573.

48. Klein AS, Brass HUC, Klebl DP, Classen T, Loeschcke A, Drepper T, Sievers S, Jaeger KE, Pietruszka J. Preparation of cyclic Prodiginines by Mutasynthesis in Pseudomonas putida KT2440. Chembiochem. 2018;19(14):1545-52.

49. Ji S, Sun R, Xu K, Man Z, Ji J, Pu Y, Yin L, Zhang J, Pu Y. Prodigiosin induces apoptosis and inhibits autophagy via the extracellular signal-regulated kinase pathway in K562 cells. Toxicol in Vitro. 2019;60:107-15.

50. Grimont PA, Grimont F. Biotyping of Serratia marcescens and its use in epidemiological studies. J Clin Microbiol. 1978;8(1):73-83.

51. Di Venanzio G, Stepanenko TM, Garcia Vescovi E. Serratia marcescens ShIA pore-forming toxin is responsible for early induction of autophagy in host cells and is transcriptionally regulated by RcsB. Infect Immun. 2014;82(9):3542-54.

52. Liu W, Zhuang J, Jiang Y, Sun J, Prinz RA, Sun J, Jiao X, Xu X. Toll-like receptor signalling cross-activates the autophagic pathway to restrict Salmonella Typhimurium growth in macrophages. Cell Microbiol. 2019: 21(12):e13095 
53. Masud S, van der Burg L, Storm L, Prajsnar TK, Meijer AH. Rubicondependent LC3 recruitment to Salmonella-containing Phagosomes is a host defense mechanism triggered independently from major bacterial virulence factors. Front Cell Infect Microbiol. 2019;9:279.

\section{Publisher's Note}

Springer Nature remains neutral with regard to jurisdictional claims in published maps and institutional affiliations.

Ready to submit your research? Choose BMC and benefit from:

- fast, convenient online submission

- thorough peer review by experienced researchers in your field

- rapid publication on acceptance

- support for research data, including large and complex data types

- gold Open Access which fosters wider collaboration and increased citations

- maximum visibility for your research: over $100 \mathrm{M}$ website views per year

At $\mathrm{BMC}$, research is always in progress.

Learn more biomedcentral.com/submissions 